\title{
ATTRv: a Multisystemic Disease Requires a Multiprofessional Approach
}

Carolina Lavigne Moreira ${ }^{1}$ and Wilson Marques Júnior ${ }^{1,2}$

Faculdade de Medicina de Riberão Preto, Universidade de São Paulo, ${ }^{1}$ São Paulo, SP - Brazil

Instituto Nacional de Ciência e Tecnologia em Medicina Translacional (INCT-TM), ${ }^{2}$ Ribeirão Preto, SP - Brazil

Pathogenic variants of the transtiretin gene (TTRv) result in the production of amyloidogenic fibrils that deposit in the extracellular space of many tissues, resulting in amyloidogenic multisystemic disease (ATTRv). Several tissues may be affected in different combinations, including the peripheral nerves and the cardiac system, which are usually the main targets, but also the kidneys, eyes, gastrointestinal system, central nervous system and musculoskeletal structures. ${ }^{1}$

ATTRv is a progressive disease ${ }^{2}$ that results in death around 8 to 15 years after the onset of the disease, even more rapidly when the cardiac system is involved early. ${ }^{3}$ However, the natural history of the disease has changed with the introduction of treatments that, by different mechanisms, decrease the production of amyloid fibrils. ${ }^{4}$

Such a complex disease demands coordinated multiprofessional interaction in order to provide the best care for patients. Considering medical specialties, well trained cardiologists, neurologists, ophthalmologists, gastroenterologists, nephrologists and geneticists should work in close collaboration both to treat patients who have already manifested the disease and to follow asymptomatic carriers, in order to detect the disease onset, when treatment is much more effective. For the best care, however, in addition to professionals who are trained in the field of amyloidosis, it is necessary that an institution is able to provide a complex set of prepared investigations, including neurophysiology (including small fiber evaluation), skin biopsy, other types of biopsy, magnetic resonance imagine, and scintigraphy.

For these reasons, we believe these patients should be followed in tertiary reference centers that should interact closely with local physicians, in order to offer the best care at the best time to patients with this complex disease.

\section{Keywords}

Cardiomyopathy; Polyneuropathy; Transthyretin; TTR.

Mailing Address: Wilson Marques Junior •

Departamento de Neurociências e Ciências do Comportamento. Hospital das Clinicas da Faculdade de Medicina de Ribeirão Preto. Campus da USP - Monte Alegre. Av. Bandeirantes, 3900. Postal Code: 14049-900, Ribeirão Preto, SP - Brazil.

E-mail:wmjunior@fmrp.usp.br

Manuscript received September 19, 2021, revised manuscript September 26, 2021, accepted September 26, 2021.

DOI: https://doi.org/10.36660/abchf.20210026 


\section{Editorial}

\section{References}

1. Koike H, Katsuno M. Transthyretin Amyloidosis: Update on the Clinical Spectrum, Pathogenesis, and Disease-Modifying Therapies. Neurol Ther. 2020;9(2):317-33. doi: 10.1007/s40120-020-00210-7.

2. Adams D, Coelho T, Obici L, Merlini G, Mincheva Z, Suanprasert N, et al. Rapid Progression of Familial Amyloidotic Polyneuropathy: A Multinational Natural History Study. Neurology. 2015;85(8):675-82. doi: 10.1212/ WNL.0000000000001870.
3. Adams D, Ando Y, Beirão JM, Coelho T, Gertz MA, Gillmore JD, et al. Expert Consensus Recommendations to Improve Diagnosis of ATTR Amyloidosis with Polyneuropathy. J Neurol. 2021;268(6):2109-22. doi: 10.1007/ s00415-019-09688-0.

4. Russo M, Gentile L, Toscano A, Aguennouz M, Vita G, Mazzeo A. Advances in Treatment of ATTRv Amyloidosis: State of the Art and Future Prospects. Brain Sci. 2020 Dec 9;10(12):952. doi: 10.3390/ brainsci10120952. 